This PDF is a selection from a published volume from the National Bureau of Economic Research

Volume Title: Innovation Policy and the Economy, Volume 9

Volume Author/Editor: Josh Lerner and Scott Stern, editors

Volume Publisher: University of Chicago Press

Volume ISBN: 0-226-40071-9

Volume URL: http://www.nber.org/books/lern08-1

Conference Date: April 15, 2008

Publication Date: February 2009

Chapter Title: Intellectual Property as a Bargaining Environment

Chapter Author: Joseph Farrell

Chapter URL: http://www.nber.org/chapters/c8183

Chapter pages in book: (39 - 53) 


\title{
Intellectual Property as a Bargaining Environment
}

\author{
Joseph Farrell, University of California, Berkeley
}

\section{Executive Summary}

Intellectual property policy relies on bargaining in the shadow of exclusivity. But bargaining is generically less than fully efficient, and the bargaining that would be needed to reach efficient arrangements in the shadow of exclusivity may be especially difficult in certain ways. I explore these issues and illustrate with brief discussions of patent pools and standards organizations, among others.

Property rights, including intellectual property rights (IPR), are typically best seen as a basis for negotiation, not a prescription for who actually uses what assets or ideas. How smoothly does such negotiation work in intellectual property, what does that imply about the IPR system's performance, and how can we make it work better?

These issues arise at several levels. Most simply, licensing (or the authorized sale of infringing products) is contracting in the shadow of the right to exclude. A patent's classical ex post deadweight loss is thus, in a modern economic perspective, the result of negotiation failures and, thus, depends on the negotiation environment.

The same is true of losses, or gains, from patent protection in an area of cumulative invention. If initial innovators and subsequent innovators negotiate smoothly and well, cumulative invention might actually be helped by broad "prospect" patents. If not, patent control of prospects can hinder cumulative invention (see, e.g., Kitch 1977; Scotchmer 1991). Thus the patent system's dynamic innovation performance, as well as its ex post deadweight losses, hinge on the efficacy of negotiation.

If it can work well enough, a deeper ex ante negotiation might even repair a dysfunctional intellectual property (IP) system or tailor it to an industry. If patents are too easy to get in electronics, or too broad in genetics research, can interested parties agree in advance to cross-license 
patents or not to seek them, and thus put themselves under a "private law" that weakens the otherwise excessive protection given by the default rules? Even more intriguingly, what if patents are too hard to get, or do not last long enough, in some other industry? Can such an industry negotiate its way to stronger IP protection?

Such negotiations, perhaps particularly the last kind, could be threatening rather than promising: privately negotiated "solutions" can be anticompetitive. Ideally, policy might try to facilitate only beneficial negotiations, but here I assume that private agreements not "caught" by antitrust screening are mostly beneficial, so (with antitrust review in place) it makes sense to ask how to facilitate negotiations. ${ }^{1}$

Are efficient negotiations in the shadow of IP rights difficult; do they need facilitation? As I describe below, I think they often are. If all private negotiations about innovation were easy, no government-sponsored IP system would be necessary: potential innovators and potential beneficiaries could just negotiate private arrangements. To discuss how to facilitate efficient private negotiation, it is helpful first to review (briefly) what modern economics treats as the main generic barriers to it.

\section{Barriers to Efficient Negotiation}

The modern economics of negotiation identifies several kinds of barrier to efficient negotiations.

\section{Contracting Problems}

Negotiations seek to solve a problem through an agreement, or contract, about how the parties will behave. If a contract cannot be enforced, or if key aspects of the parties' behavior cannot be specified in an enforceable contract, then negotiation cannot solve the problem. Innovation policy suggests a couple of examples:

- First, market-like mechanisms such as patents may be desirable in part because simple reimbursement or prize contracts for research might not well-targetedly specify what problems should be worked on, when, or how hard.

- Second, consider the economics of patent holdup. A contract cannot guide past behavior, so delayed negotiations cannot fully substitute for prompt negotiations. Even if delayed negotiations will be fully efficient when they take place, they will generally reflect shifts in bargaining 
positions due to investments and commitments meanwhile. And if that effect is anticipated, it creates inefficient incentives. ${ }^{2}$

\section{Information Asymmetry}

In the simplest bilateral negotiation between a technology user and the holder of a known patent, modern economics attributes failure to trade efficiently to "private" or "asymmetric" information. If, for example, a patent holder thinks a buyer may well be willing to pay $\$ 100$ for a license, but the buyer knows he is only willing to pay $\$ 50$, negotiations may fail. Even when neither party is certain of the value of a license, if their information/ignorance is symmetric-for instance, if the value depends on economic variables that neither yet knows - the theory of bilateral bargaining suggests that efficient outcomes are much more likely.

Information asymmetry is likely to be reduced when more information is publicly available. Thus it would seem that ex post licensing negotiations should, on average, go more smoothly if more information on patent validity were brought out publicly at an early stage, as perhaps by more thorough Patent Office examination, and/or an early opportunity for public opposition. ${ }^{3}$

One common and intuitively difficult information problem arises when a producer does not know with whom it must negotiate concerning patents. One might call this a "potential-patent thicket," as distinct from the "actual-patent thicket" that can create multiple-marginalization problems when many patents are known to be infringed by a product. If a technology user cannot even list the patent holders who can block its product, negotiation will be very difficult.

\section{Large Numbers and Holdout}

Negotiations that fundamentally involve many players are difficult. By this I mean negotiations in which many participants must cooperate for a common goal-as, for instance, a patent pool involving many patent holders-as distinct from a cluster of many fundamentally bilateral deals, as when a single patent holder licenses its patent to many users. Fundamentally multilateral negotiations are difficult for two reasons that interact in a subtle fashion. This is an aspect of the economics of bargaining that, while no doubt well understood by bargaining experts, is not a core part of economists' general education as the contracting and information issues are. 
In multilateral bargaining, it is a key question whether (as in bilateral bargaining) a successful negotiation requires unanimity or whether partial accords can be implemented. If nothing will be done without full participation, then each player will compare his proposed payoff under an agreement versus the status quo. If the agreement increases participants' total surplus, then there is a way to divide up the gains so as to make everyone better off and command unanimous assent. The difficulty then arises because of information problems: even if we know that joint surplus increases, it may be hard to find that way to make everyone better off. A symmetric draft agreement that divides the gains equally will command unanimous assent only if the gains per participant exceed the maximum among the $N$ participants' costs of participation. This order statistic is likely to be well above the average, and agreement may very well fail even though the total gains easily exceed $N$ times the average cost of participation.

What if a proposed agreement is structured so as to be less fragile, more robust, than that? What if it is set up with the hope that all $N$ will participate, but if not, an incomplete agreement with only $N-1$ participants is on the cards? Then the incentive condition for it to be an equilibrium for everyone to join in is no longer that the proposed agreement is better for all than the status quo. Now, the condition is that the proposed agreement is better for each player than having the other $N-1$ players implement an incomplete agreement. When a partial agreement benefits the nonparticipating (holdout) player, then this condition is harder to satisfy than the simple "benefits all relative to status quo" condition. As a result, a full agreement might be impossible if partial agreements would occur. We will see some IP examples below. Diplomacy in fundamentally multilateral negotiations, when partial agreements benefit nonparticipants, can thus involve persuading everyone that he is pivotal (no agreement will occur without him), and either being skilled at finding the way to make everyone better off than the status quo or else arranging that, despite appearances, not everyone is in fact pivotal, so that a partial agreement might be rescued. ${ }^{4}$

In the following sections I discuss three private patent institutions: patent pools, standard-setting organizations, and prospective cross-licenses or grantbacks. One can view each as a privately negotiated response to a dysfunction in how the default patent policy operates in a particular zone. I discuss how public policy might help such an institution overcome bargaining problems that it faces. I also ask whether we can draw broader policy lessons from the fact that private parties are motivated to build these institutions. I then address whether negotiations to privately 
strengthen patent protection are fundamentally different from negotiations to privately weaken it.

\section{Patent Pools}

When multiple patents controlled by different owners bear on a product, there will generically be a multiple-marginalization problem. If each patent owner negotiates a royalty with producers of the product, the result will tend to be a total royalty higher than the patent holders collectively would prefer. Multilateral negotiation could produce a better result for them-and the producers and downstream customers presumably would also prefer it, since it involves a lower royalty. Sometimes (the prospect of) this dysfunction prompts the formation of a patent pool. ${ }^{5}$

Patent pools face bargaining problems. An obvious one is a privateinformation problem: each participant might claim that its patent is worth more than others', but it will be difficult to negotiate who should get how much (and indeed patent pools sometimes instead adopt a rule of thumb, such as payouts proportional to the number of patents contributed).

As our discussion of multilateral negotiations suggests, another problem arises if potential members do not believe they are pivotal. In fact, patent pools often include only some, not all, of the patents needed for a product: apparently potential participants often are not pivotal. If a patent holder does not expect to be pivotal, its reservation payoff in order to join a pool that it expects to attract all others is its "dream" value of setting its preferred royalty while others rein theirs in. (This is akin to the oligopolist's dream payoff of having its rivals form a cartel and raise their prices, with no obligation to limit its own.) It can-and, in the symmetric case, must-be impossible to create enough joint surplus to give each patent holder this dream payoff. If so, a full patent pool is either infeasible or fragile (not robust to small-scale defections). Note, moreover, that the royalty-stacking problem is apt to be most severe when there are many separate patent owners, which is also where the negotiation problems in forming a private patent pool are apt to be most severe.

\section{Policy Responses?}

If patent pools (subject to manageable antitrust scrutiny) are beneficial but face significant bargaining obstacles, is the right policy response 
simply to permit those that successfully form? Perhaps policy could go further and help overcome those obstacles.

As usual, one expects that private information, perhaps especially about the set of relevant patents, will hinder efficient bargaining, and large numbers make for a harder problem through the order-statistic effect. Generic policy implications include patent clarification and limiting unnecessary patents.

Policy might try to address the holdout problem either $(a)$ by making participants feel more likely to be pivotal or $(b)$ by otherwise trying to hold holdout payoffs closer to the no-agreement benchmark.

a. An obvious policy concern with this strategy is that, when there is also private information, it is not clear that we should try to make beneficial agreements fragile. However, it seems worth considering at least making covert holdout difficult by publicly clarifying the set of relevant patents (both clarity of the rights and clarity of the list of rights holders). Clarity of patent rights could be improved, as Bessen and Meurer (2007) argue.

$b$. Obviously many policies could limit a holdout's payoff, but merely aiming to lower that payoff would be too blunt an approach. Rather, the idea would be to bring it closer to a level commensurate with the patent's normal value, eliminating only the incremental gain from holdout. Implementing this idea would be difficult (and no doubt raise other problems) but perhaps not impossible. Thus, suppose that a partial patent pool forms and ameliorates a royalty stacking or transactions cost problem, so that a producer can license many of the relevant patents for a modest sum and with one transaction. Now suppose that a holdout patent holder who chose not to join the pool sues a producer for patent infringement and wins. How should damages be calculated? A patent holder has a holdout incentive to stay out of the pool if its prospective damages are based on the pool-boosted success of the product; this could be neutralized if damages are instead based on an estimate of sales if there had been no pool, giving the patent holder incentives to join as if it were pivotal, even if it were not. ${ }^{6}$

A different approach to holdout problems is used in some other areas of law and policy such as land law and corporate finance. In land law, the concept of "eminent domain" is sometimes used-with muchdebated safeguards, to be sure-so that a project that needs a large chunk of land can acquire some of it through compulsory purchase and not be 
vulnerable to holdout or to holdup. In corporate finance, when a raider acquires a sufficient share of a firm, it may be able to force remaining shareholders to sell (see, e.g., Yarrow 1985).

These would be attempts to smooth the private negotiations. Another response could be to learn. This is not perhaps as simple as it sounds. If we observe partly successful negotiations, an optimist may conclude that, while royalty stacking might in principle be a problem, behold: the market finds a solution-perhaps incomplete, but perhaps that just suggests that the residual problem is small. A pessimist may conclude that the problem is only imperfectly subject to privately negotiated solutions. Both inferences make some sense. It is true that large gains from trade, other things equal in the relevant sense, are more likely to overcome bargaining problems. It is also true that the royalty-stacking problem is most severe when both the number of patent holders and the impact of each one on demand are greatest, making the negotiation especially hard. A sensible response might be to recognize that the private solution is unlikely to be perfect and to minimize the burden put on it, for instance, by limiting the number of patents. ${ }^{7}$

\section{Standard-Setting Organizations}

Standard-setting organizations (SSOs) and their members can face problems when it is belatedly learned that a compatibility standard infringes a patent. License negotiation ex post (after commitments to a standard are made) is often a poor substitute for the more appropriate ex ante negotiation (see, e.g., Lemley and Shapiro 2007). This problem is not unique to standard setting but can be particularly severe there. There are likely to be consumer benefits when SSOs try to address the problem. ${ }^{8}$ But in doing so the SSO is constrained both by contracting problems and by negotiation constraints.

One contracting problem is, again, identifying with whom agreements are needed. Another is to specify who should search how hard for potentially relevant patents and what should be disclosed when. Perhaps the most fundamental is that tradition and concerns about antitrust liability encourage the use of bilateral licensing negotiations, while the choice of a standard is inherently a predominantly collective choice. Thus there is a mismatch between the locus of licensing negotiations and the ability to substitute among technological alternatives. This mismatch, among other forces, encourages the substitution of a commitment to "reasonable and nondiscriminatory" licensing terms for more 
specific ex ante negotiations. But a commitment to "RAND" raises problems of contract interpretation ex post.

The negotiation constraints, somewhat as in the holdout problem with patent pools, arise from the fact that a patent holder may well be able to get a nonparticipation payoff that exceeds the payoff it would get under the fully efficient arrangement. In the standards instance, it would do so by avoiding membership obligations (quitting, or not joining, the SSO, for instance) and hoping, or maneuvering, for the standard to be covered by its patent and to be entrenched before it negotiates licenses. A voluntary membership organization cannot then contract into the fully efficient arrangement: that would risk a refusal to "participate" by patent holders. Their participation constraint, in the language of the economics of bargaining, constrains the agreement away from the first-best.

\section{Policy Responses?}

If this is a good description of what SSOs are wrestling with, what might policy do? ${ }^{9}$ Antitrust agencies could helpfully calm SSOs' arguably overblown antitrust fears about collective ex ante royalty negotiation. Both the Department of Justice and the Federal Trade Commission have taken steps in this direction.

Courts could also try to clarify the meaning and enforcement of the "reasonable and nondiscriminatory" (RAND) policies adopted by many SSOs, when patents subject to that promise are litigated. In the spirit of the Georgia-Pacific rule on reasonable royalties, the right concept presumably is the royalties that would have been negotiated between a willing licensor and the willing members of a willing SSO at the time the choice to use a (potentially) infringing technology was made. ${ }^{10}$ As in the suggestion above about damages in cases involving an incomplete patent pool, the motivating idea is to allow for normal negotiations but stripped of the holdout/holdup element. This could be viewed as simply contract interpretation where there is a "RAND promise."

But the learning perspective suggests a case for going further. If the members of an SSO agree to address holdup by requiring disclosure and RAND promises, what might public policy learn from that? The optimist's learning perspective might be that this is the "market solution" and need only be narrowly enforced. The less optimistic (and, I think more credible) inference is that this is as far as the SSO feels able to go in dealing with a significant problem, given perceived antitrust constraints and the voluntary nature of the SSO. By recognizing the 
problem and limiting patent holdup by nonparticipants (or by participants exploiting gaps in the rules), outside policy could not only perhaps improve outcomes in the instance but also empower an SSO to craft rules that more fully address the problem.

These ideas, whatever their practical merits or demerits, illustrate conceptually how policy responses can go beyond merely permitting, when a private arrangement seems beneficial but is constrained by bargaining problems. One might learn from the private arrangement something about the nature or severity of the problem or about possible techniques to address it. Relatedly, one might try to improve the prospects for successful bargaining by improving information, improving contractibility, and limiting the extent to which holdout parties can exploit the problem-especially the extent to which their ability to do so might be enhanced by others' partial solutions.

\section{Negotiating IP Downward}

Here I briefly describe three cases in which private parties sought to weaken the effects of default patent policy on a going-forward basis. Many observers think that the historic pattern of broad cross-licensing in the electronics industry (see, e.g., Hall and Ziedonis 2001; Shapiro 2004) was a helpful response to the patent thicket problem and regret that it has weakened in the face of the greater bargaining challenges that arise when there are more, and a more open-ended set of, players. Yet a superficially similar arrangement among auto manufacturers in pollution control technology was challenged by the Department of Justice. ${ }^{11}$ Finally, I comment on the FTC's challenge to parts of Intel's intellectual property policy.

\section{Cross-Licensing in Electronics}

In the electronics industry, many think that patents are as apt to hinder innovation as to promote it. For some time, major established players largely neutralized some aspects of the patent system among themselves by agreeing to broad cross-licenses: I'll call this their Big Deal (see, e.g., Parchomovsky and Wagner 2005). They were thus able to design products (including innovating) with much less role for intellectual property than under the default rules.

Many observers think the Big Deal has broken down—not completely, but substantially. From a bargaining point of view, two plausible hypotheses might help explain how such a system would break down. 
Balance of interests/opportunism. For the Big Deal to remain incentive compatible, each participant must value the resulting "design freedom" more than its alternatives. If the alternative were an efficient reward to its patents, this fact would merely constrain the Big Deal to giving each pivotal participant more than its status quo payoff, which would be a test for efficiency, and to giving each nonpivotal participant more than its alternative payoff, which could be more demanding than the efficiency test, much as it was in the patent pool context. But a further holdout problem with the Big Deal arises if there is also a holdup problem, as discussed in the standard-setting context. Then, a nonmanufacturing patent holder can get more than its patent's inherent value by declining to participate.

Open-ended set of participants. Negotiating with a heterogeneous set of rivals may be difficult, but one would expect that it would be even more difficult to negotiate when new participants may show up unexpectedly at any time. Intuitively, one does not know whom one has to negotiate with. ${ }^{12}$ This makes it hard to achieve the "design freedom" that the Big Deal provided among insiders.

\section{Cross-Licensing in Automotive Pollution Control}

While many observers regret the decline of the Big Deal in electronics, the Justice Department sued a group of automobile manufacturers who had agreed on such a policy in pollution control equipment, on the grounds that the agreement eliminated competition among them in developing such equipment. ${ }^{13}$ However, in 2001, FTC Chairman Pitofsky described this as the only federal government challenge to a research joint venture since the passage of the Sherman Act, suggesting that, while liberal cross-licensing could be harmful, policy intervention to stop it is generally unlikely.

\section{Intel's IP Practices}

The FTC sued Intel over its practice of withdrawing key IP from its customers if they sued Intel for infringing their patents. FTC Chairman Pitofsky described the case as follows.

In one of the most widely noted antitrust enforcement actions involving intellectual property, the Commission in 1998 issued a complaint against the Intel Corporation alleging that it was a monopolist in the microprocessor market and that it had sought to maintain its dominance 
by denying essential technical information and product samples of new microprocessors to companies that, because of intellectual property disputes, had initiated or threatened to initiate litigation against Intel or Intel's customers. Intel's goal, according to the complaint, was to coerce other companies not to resort to the courts, but instead to license their intellectual property on terms favorable to Intel. Intel had previously provided the information and samples to many of its customers and customer-competitors, but withdrew these advantages from those who found themselves in IP disputes with Intel. The Commission alleged that anti-competitive effects included discouraging innovation efforts by potential challengers in microprocessor technology.

In settling the case, Intel agreed not to withhold or threaten to withhold product or technical information for reasons relating to an intellectual property dispute. The Commission agreed to qualify this provision however, by acknowledging that an intellectual property holder, including a monopolist like Intel was alleged to be, is free not to license its product or information in the first instance, but ought not to be able to curtail its supply when the customer seeks to vindicate its intellectual property rights through a range of legal and equitable remedies. Intel was also free to discontinue a license when a customer or competitor sought an injunction against Intel's sale of its microprocessors. The order gave the challenger a choice of waiving that remedy, or, if it refused to waive, allowed Intel to discontinue providing information or product.

The goal of the order was to avoid a "compulsory licensing" regime, even by an alleged monopolist, because of the adverse effects of such regimes on innovation. The order was designed to allow Intel and its challengers to vindicate their rights in court before an independent adjudicator, rather than resort either to self-help (by Intel) in which case the strong would almost always vanquish the weak, or to the kind of injunction (by Intel's challenger) that would threaten Intel's ability to conduct its business. ${ }^{14}$

\section{Negotiating IP Upward}

The privately negotiated departures from default rules above are in the direction of less protection, more ex post competition, and perhaps less ex ante incentive to get patents. What about negotiations in the opposite direction-negotiations to strengthen or create "intellectual property"? In general, I think, public policy takes a more skeptical view of such negotiations than of negotiations in the direction of less protection. 
- Suppose that the top pharmaceutical companies claimed that patent protection should be longer and stronger than it is and agreed that (a) none of them will challenge the validity of any patent held by another and $(b)$ none will infringe another's expired patent until it has been expired for at least 5 years.

- Or suppose that the largest airlines agreed that, to encourage the "innovation" of flying new routes, they would create a private patent-like policy: none would enter a "new" route on which another was offering nonstop service, perhaps defining a "new" route as one on which no such service was offered as of the date of the agreement.

Such agreements would of course face a private negotiation problem in that nonsignatories could challenge patents or decline to respect the prolonged patent life or the airline route agreement. Thus it would probably not be profitable for a small subset of firms that collectively lack market power to negotiate such an agreement, even if IP really is too weak in their industry to the detriment of profits as well as welfare.

If a group of firms who were not too concerned about outsiders were to reach such an agreement, on the other hand, this agreement would likely be treated as an antitrust violation because it limits ex post competition-even though it could strengthen incentives to innovate. As both ex post competition and ex ante incentives to innovate are good for consumers, why should we view negotiated departures from Congress's default balancing in one direction much more suspiciously than in the other?

One possible answer is that we do not. Private policies have been attacked for weakening IP, in the motor manufacturers case and in the FTC's complaint against Intel. And one can view some antitrust justifications for exclusive dealing as strengthening incentives to "invest," perhaps in innovation, by agreeing to limit ex post competition (see, e.g., Segal and Whinston 2000). Despite these comebacks, however, I think the general trend stands.

Another possible answer is that such deals are often applied to a substantial installed base, not only prospectively, so that they have more of the adverse ex post effect than of the potentially beneficial ex ante effect. For example, the hypothetical pharmaceutical deal might apply to existing patents as well as to new research. ${ }^{15}$

A more intriguing possible answer would be that we should not think of the default rules as correctly (or congressionally) calibrated for the average industry or environment. Despite bargaining difficulties, private parties may well be better able to weaken IP by contracting-around 
than to strengthen (or introduce) IP by contracting-around. Or, it might be about equally easy to do, but significantly easier for competition policy to diagnose as beneficial or not. If so, then up to a point it might make sense for the default policy to be calibrated not as an attempt to approximate the best overall policy but as something distinctly biased toward strong protection and to allow, and/or expect, many private weakenings but few strengthenings.

\section{Conclusion}

Private arrangements, both short-run (licensing an existing patent) and longer-run, in the shadow of patent law can be beneficial. The conventional approach permits these (unless they seem harmful) but does not actively try to help them come to fruition. Because private negotiations often face significant bargaining difficulties, modern bargaining theory suggests scope for policy to smooth their way. We can also learn about policy tradeoffs from both successful and unsuccessful private negotiations.

\section{Endnotes}

I thank Pamela Samuelson, Carl Shapiro, and the editors for helpful comments, and the editors for their patience.

1. The assumption that, with manageable antitrust screening, most agreements in the shadow of IP rights are beneficial is implicit in the approach suggested by the FTC/DOJ Guidelines for the Licensing of Intellectual Property.

2. Some policy commentators suggest that only "surprise" holdup is a problem: if its victims know that holdup is likely, they know what they are getting into, so the law need not assist them. Cases in which holdup actually occurs are indeed cases in which one possible adverse effect of the prospect of holdup, namely, the victims choosing not to develop products or standards, has not happened (although development might have been delayed or less ambitious than otherwise). But other interim investments may well have been deterred. By contrast, it is not so easy to identify specific impacts on economic efficiency of holdup that is truly a surprise, except that what is a surprise this time will change people's expectations of what may happen next time.

3. A separate point is the one I make with Carl Shapiro (2008), that the terms and structure of licenses successfully negotiated under symmetric uncertainty about patent validity may also be problematic.

4. This does not, of course, tell us what will happen, but it does imply that a broad agreement is hard to sustain.

5. For a recent study of patent pools, see Lerner, Strojwas, and Tirole (2007).

6. This would surely be error prone, but if the goal is to repair the bargaining incentives, it would be enough to get the holdout's expected payoff right. Making each patent holder's holdout payoff equal to what it would be if there were 
no pool should (in theory) ensure that there will be pool shares and prices that make the pool attractive to all members of any set $S$ of patent holders if and only if there are joint gains to the formation of a pool containing $S$. However, subtle issues of coalition formation may also arise, so at this point I would regard the idea in the text as a hypothesis or conjecture to be worked out.

7. Patent pools of course can be anticompetitive, at least if the patents are substitutes rather than complements, so it is also sensible to think of limiting the number necessary as well as their scope and complexity, to facilitate antitrust review if nothing else. Improvements in patent quality would presumably help along these lines.

8. For discussions of standard-setting organizations' policies, see, e.g., Lemley (2002), Chiao, Lerner, and Tirole (2007), or Farrell et al. (2007). As noted in that article, I have consulted in this area and continue to do so.

9. I do believe that generally this is what is going on. But it is worth keeping in mind that an SSO could potentially become a "rogue" organization, acting either as an inefficiently monopsonistic technology buyers' cartel or as a tool of collusion against downstream customers. Thus simply giving SSOs much more power might not be a good answer.

10. The Georgia-Pacific decision talks about a hypothetical negotiation at the time that infringement began. In the standards context this may be quite different from when the choice was effectively made, but it seems to me that the core logic favors looking at the time of choice, not of first legal infringement.

11. This is a case from the 1960s and was settled rather than fully litigated, but the department cited the case in its 1995 Guidelines.

12. In a different context, it may be hard to find rights holders for copyrights on old books. Apparently it is not unusual for copyright to revert to an author when a publisher allows a book to remain out of print, but authors may be dead or hard to locate.

13. United States v. Automobile Manufacturers Association, 307 F. Supp. 617, 618 (C.D. Cal. 1969) (approving consent decree settling charges of conspiracy "to eliminate competition in the research, development, manufacture and installation of motor vehicle air pollution control equipment" in violation of Section 1 of the Sherman Act), aff'd in part and appeal dismissed in part, 397 U.S. 248 (1970).

14. For a different angle, see Shapiro (2004).

15. Some nonhypothetical deals under which a pharmaceutical patent holder pays a potential entrant to stay out have been challenged by the FTC. These of course are in the first instance ex post deals, with a less clear link to ex ante incentives.

\section{References}

Bessen, James, and Steven Meurer. 2007. Patent Failure. Princeton, NJ: Princeton University Press.

$\rightarrow$ Chiao, Benjamin, Josh Lerner, and Jean Tirole. 2007. "The Rules of Standard Setting Organizations: An Empirical Study." RAND Journal of Economics 38 (Winter): 905-30.

Farrell, Joseph, John Hayes, Carl Shapiro, and Theresa Sullivan. 2007. "Standard Setting, Patents, and Hold-up." Antitrust Law Journal 74, no. 3:603-70. 
$\rightarrow$ Farrell, Joseph, and Carl Shapiro. 2008. "How Strong Are Weak Patents?" American Economic Review 98 (September): 1347-69.

$\rightarrow$ Hall, Bronwyn, and Rosemary Ziedonis. 2001. "The Patent Paradox Revisited." RAND Journal of Economics 32:101-28.

$\rightarrow$ Kitch, Edward. 1977. "The Nature and Function of the Patent System." Journal of Law and Economics 20:265-90.

$\rightarrow$ Lemley, Mark. 2002. "Intellectual Property Rights and Standard Setting Organizations." California Law Review 90, no. 6 (December): 1889-1980.

Lemley, Mark, and Carl Shapiro. 2007. "Patent Holdup and Royalty Stacking." Texas Law Review 85:1991-2049.

$\rightarrow$ Lerner, Josh, Marcia Strojwas, and Jean Tirole. 2007. "The Design of Patent Tools: The Determinants of Licensing Rules." RAND Journal of Economics 38, no. 3:610-25.

Parchomovsky, Gideon, and R. Polk Wagner. 2005. "Patent Portfolios." University of Pennsylvania Law Review 1:154.

$\rightarrow$ Scotchmer, Suzanne. 1991. "Standing on the Shoulders of Giants: Cumulative Research and the Patent Law." Journal of Economic Perspectives 5:29-41.

$\rightarrow$ Segal, Ilya, and Michael Whinston. 2000. "Naked Exclusion: Comment." American Economic Review 90, no. 1 (March): 296-309.

Shapiro, Carl. 2004. "Technology Cross-Licensing Practices: FTC v. Intel (1999)." In The Antitrust Paradox, ed. John Kwoka and Lawrence White. Oxford: Oxford University Press.

$\rightarrow$ Yarrow, George K. 1985. "Shareholder Protection, Compulsory Acquisition, and the Efficiency of the Takeover Process." Journal of Industrial Economics 34 (September): 3-16. 
